\title{
The evolutionary game analysis of cross-regional ecological compensation - based on the perspective of the main functional area
}

\author{
PAN He-si ${ }^{1}$, LIU Hong-zhi ${ }^{*}$ \\ ${ }^{1}$ School of Economics and Management, Northeast Forestry University, Haerbin 150040, China \\ ${ }^{2}$ Institute of Business Economics, Harbin University of Commerce, Harbin 150028, China
}

\begin{abstract}
Under the new normal, the carrying capacity of ecological environment in China has reached or approached the upper limit. The root cause is the lack of an endogenous mechanism for the protection and compensation of forest resources. Therefore, clarifying the game relationship between stakeholders can help to break through the dilemma. An evolutionary game model between beneficiary regions and the protected regions was constructed, based on the "restraint-encouragement" mechanism of the central government.The results show that in cross-regional ecological compensation, the optimal strategy of "protectioncompensation" depend on the net profits of local governments and the central government's fines.
\end{abstract}

\section{Introduction}

Ecological environment is the basis for human survival and socio-economic development, and it is also the basic condition for the construction of ecological civilization. China has divided the land space into four main functional areas: optimized development, key development, restricted development, and prohibition of development based on regional resource endowments, natural conditions and environmental carrying capacity, etc. The central government has explicitly proposed to "implement the compensation system for ecological resources and the ecological compensation system"in view of the restriction and prohibition of ecological function zones. As a result, local governments and residents lack the enthusiasm for ecological environmental protection, and the goal of national ecological protection is difficult to implement.

The ecological compensation mechanism is to regulate the interests of related parties and internalize the external effects of ecological services, reflecting the principle of fairness and efficiency ${ }^{[1]}$. In addition, due to the need for survival and development in backward areas, local management departments may "collaborate" with the government to maximize the economic benefits by sacrificing the quality of resources and environment ${ }^{[2]}$.It can be seen that cross-regional ecological compensation is not only a technical problem, but also a dilemma under the influence of different interest appeals and behavior-oriented conflicts of complex stakeholders ${ }^{[3]}$. Therefore, the theory of evolutionary game has been widely used by scholars at home and abroad to reveal the conflicts of interests and actions of multilateral entities ${ }^{[4]}$.Jichuan ${ }^{[5]}$ constructed an game model of forest ecological compensation between developing and developed countries, and analyzed the evolutionary stabilization strategies of implementers and beneficiaries of REDD+ projects under different scenarios. Based on the asymmetric game model, Feng ${ }^{[6]}$ studied the evolutionary phase diagram and evolutionary stability strategy of the main stakeholders in the Yangtze River Basin in China. However, there is lack of research applying game theory models to study ecosystem services payment behavior ${ }^{[7-8]}$ (Engel and Palmer, 2008). Smith and Price (1973) ${ }^{[9]}$ first proposed an evolutionary game model; it describes the evolutionary dynamics of a well-mixed population, consisting of individuals that interact using different strategies ${ }^{[10]}$. The evolutionary game model is effective for analyzing competition between co-operators and defectors ${ }^{[11-12]}$.

From the existing studies, few scholars scholars have studied the issue of trans-regional ecological compensation from the perspective of macro-functional regions. In view of this, this paper builds an evolutionary game model of inter-regional regional government based on the central government's constraint-motivation mechanism to reveal the decision-making basis and driving mechanism of multi-subjective behavior in China's trans-regional forest ecological compensation, and provide theoretical reference for improving forest ecological compensation.

\section{Ecological compensation evolutionary game model after introducing constraint-incentive mechanism}

\subsection{Basic assumptions and model construction}

*Corresponding author: ${ }^{\text {a } 648519199 @ q q . c o m ~}$ 
According to the above studies, the restricted development zone and the banned development zone are mainly responsible for the protection of the ecological environment, and so they are defined as implementing groups; The key development zones and the optimized development zones are mainly responsible for economic development, and so they are defined as beneficiary groups, who enjoy spillover ecological services without any ecological input. Due to the characteristics of Chinese-style decentralization and performance appraisal system, local governments have more independent decision-making power and action space, Therefore the implementation group may choose to invest funds to protect ecological resources actively, who based on environmental policy considerations. However, in view of the economic development requirements of the region, they may also choose to undermine the rapid development of the economy at the expense of sustainable development capacity of resources, which result in a decline in the capacity of providing ecological services, and it will also have a great impact on the ecological environment in the beneficiary areas; While the beneficiary groups may be more pursuing a good ecological environment based on Maslow's level of demand theory and giving the implementation group certain ecological compensation because of the high level of economic development. Of course, the beneficiary groups may also choose no compensation due to the characteristics of ecological service spillovers and values which are difficult to quantify. Therefore, in light of the above analysis, the strategy of the implementation groups are \{protection, non-protection\}, and the strategy of the beneficiary groups are \{ compensation, no compensation\}. In the course of evolutionary games, the implementation group and the beneficiary group are the subjects of limited rationality, and each pursues the maximization of their own interests. The "protection-compensation" strategy is the optimal strategy that society expects.

The pay matrix symbol assumption of cross-regional ecological compensation evolutionary game model: L represents the ecological benefits obtained by implementing groups when they chose protecting resources; $\mathrm{C}$ represents the opportunity cost lost by the implementation group to protect the ecological environment; $\mathrm{R}_{1}$ represents the gains from the beneficiary areas when implementing the group to protect the ecological environment; $\mathrm{R}_{2}$ represents the gains from the beneficiary areas when the implementation group does not protect the ecological environment; $\mathrm{P}$ represents the ecological compensation fee paid by the beneficiary group. B indicate that when one of the implementing groups and the beneficiary groups are protected/ compensated the forests environment, which the central government will give a reward to one of them. $\mathrm{F}(\mathrm{F}>\mathrm{P})$ indicate that when one of the implementing groups and the beneficiary groups are not protected/ not compensated the forests environment, which the central government will give a punishment(in the form of fines, taxes, or carbon emissions charges) to one of them. The payout matrix of the implementation groups and the beneficiary group is shown in Table 1:
Table 1 Introducing the game payment matrix between the implementing region and the beneficiary region under the constraint-incentive mechanism

\begin{tabular}{ccc}
\hline \multirow{2}{*}{$\begin{array}{c}\text { Implementation } \\
\text { groups }\end{array}$} & \multicolumn{2}{c}{ Beneficiary groups } \\
\cline { 2 - 3 } & compensation & $\begin{array}{c}\text { Not } \\
\text { compensation }\end{array}$ \\
\hline Protection & $(\mathrm{L}+\mathrm{P}-\mathrm{C}+\mathrm{A}$, & $\left(\mathrm{L}-\mathrm{C}+\mathrm{B}, \mathrm{R}_{1-}\right.$ \\
& $\mathrm{R} 1-\mathrm{P}+\mathrm{B})$ & $\mathrm{F})$ \\
Not Protection & $\left(\mathrm{P}+\mathrm{C}-\mathrm{L}-\mathrm{F}, \mathrm{R}_{2-}\right.$ & $\left(\mathrm{C}-\mathrm{L}, \mathrm{R}_{2}\right)$ \\
& $\mathrm{P}+\mathrm{B})$ & \\
\hline
\end{tabular}

\subsection{The evolutionary stabilization strategy of ecological compensation}

Assuming that the proportion of the implementation group adopting the "protection" strategy is $\mathrm{x}$, and $1-\mathrm{x}$ is the proportion of the "unprotected" strategy. While y represent proportion of the beneficiary groups in adopting a compensation strategy, and 1-y is the proportion of non-compensation strategies.

Therefore, the expected returns and average expected returns for the implementation groups to select "protection" and "unprotection" are $\mu_{11}, \mu_{12}, \bar{\mu}_{1}$ :

$$
\begin{aligned}
& \mu_{11}=y(L+P-C+A)+(1-y)(L-C+B) \\
& \mu_{12}=y(P+C-L)+(1-y)(C-L) \\
& \bar{\mu}_{1}=x \mu_{11}+(1-x) \mu_{12}
\end{aligned}
$$

The replicator dynamic equation of implementing groups who selecting "protection" strategy is:

$$
\begin{aligned}
F(x) & =\frac{d x}{d t}=x\left(\mu_{11}-\bar{\mu}_{1}\right) \\
& =x(1-x)(y F+2 L-2 C+B)
\end{aligned}
$$

The expected returns and average expected returns for the beneficiary groups to select "compensation" and "non-compensation"are $\mu_{21}, \mu_{22}, \bar{\mu}_{2}$ :

$$
\begin{aligned}
& \mu_{21}=x\left(R_{1}-P+B\right)+(1-x)\left(R_{1}-F\right) \\
& \mu_{22}=x\left(R_{2}-P+B\right)+(1-x) R_{2} \\
& \bar{\mu}_{2}=y \mu_{21}+(1-y) \mu_{22}
\end{aligned}
$$

The replicator dynamic equation for the benefit groups who selecting the "compensation" strategy is:

$$
\begin{aligned}
F(y) & =\frac{d y}{d t}=y\left(\mu_{11}-\bar{\mu}_{1}\right) \\
& =y(1-y)(x F+B-P)
\end{aligned}
$$

The replication dynamic system of the implementation groups and the beneficiary groups are formed According to Formula (1) and Formula (2): 


$$
\left\{\begin{array}{l}
\frac{d x}{d t}=x(1-x)(y F+2 L-2 C+B) \\
\frac{d y}{d t}=y(1-y)(x F+B-P)
\end{array}\right.
$$

\section{Evolutionary Game Analysis Based on Asymmetric View}

\subsection{Analysis of the evolutionary stability strategy of the implementation groups}

Under the constraint and incentive mechanism of the central government, the dynamic equation of the replicator implementing the protection strategy of the group is:

$$
F(x)=x(1-x)(y F+2 L-2 C+B)
$$

Let $\mathrm{F}(\mathrm{x})=0$, and we know that $\mathrm{x}^{*}=0$ and $\mathrm{x}^{*}=1$ are two stable state points that duplicate the dynamic equation.

(1) If $\mathrm{y}=\mathrm{y}^{*}=(2 \mathrm{C}-2 \mathrm{~L}-\mathrm{B}) / \mathrm{F}$ and $0 \leq(2 \mathrm{C}-2 \mathrm{~L}-\mathrm{B}) / \mathrm{F} \leq 1$ holds, then $\mathrm{F}(\mathrm{x})$ is always 0 , which means when the beneficiary group selects the "compensation" strategy under the value $y=y^{*}$. there is no difference between two strategies of the benefits for the implementation groups.

(2) When $y>y^{*}=(2 C-2 L-B) / F, x^{*}=0, x^{*}=1$ is the two possible stable states of $\mathrm{x}$, and the equation $\mathrm{F}(\mathrm{x})$ is derived, so $F^{\prime}(1)<0$, that $\mathrm{x}=1$ Is an evolutionary stability strategy. That is, when the benefited area groups choose the "compensation" strategy at a level higher than the $(2 \mathrm{C}-2 \mathrm{~L}-\mathrm{B}) / \mathrm{F}$ level, the implementation group gradually tends to the "protection" strategy from the "unprotected" strategy. The "protection" strategy is an evolutionary stable equilibrium strategy. From the above equation, we can see that when $\mathrm{F}$ is larger, the condition of $y>y^{*}$ is easier to meet, it is easier to achieve the Excellent stability and balance.

(3) When $y^{<} y^{*}=(2 C-2 L-B) / F, x^{*}=0, x^{*}=1$ is the two possible stable states of $\mathrm{x}$, the derivative of the equation $\mathrm{G}(\mathrm{x})$, So $F^{\prime}(0)<0$, Therefore, $\mathrm{x}=0$ is an evolutionary stabilization strategy. That is, when the beneficiary group selects the "compensation" strategy at a level lower than $(2 \mathrm{C}-2 \mathrm{~L}-\mathrm{B}) / \mathrm{F}$, the implementation groups gradually moves from the "protection" strategy to the "unprotected" strategy. The "unprotected" strategy is an evolutionary stable equilibrium strategy.

\subsection{Analysis of Evolutionary Stability Strategy of Beneficiary Group}

The replicator dynamic equation for the benefit group to adopt the "compensation" strategy is:

$$
F(y)=y(1-y)(x F+B-P)
$$

Let $\mathrm{F}(\mathrm{y})=0$, according to the replication dynamic equation, we get two possible steady state points $\mathrm{y}^{*}=0$, $\mathrm{y}^{*}=1$.

(1) When $x^{*}=(P B) / F$, there is always $F(y)=0$, which means that there is a steady state for all y levels. In this case, when the implementation group is selected at $(\mathrm{PB}) / \mathrm{F}$ level When protecting a strategy, there is no difference in the benefits of beneficiary groups choosing the two strategies.

(2) When $x>x^{*}=(P-B) / F, y^{*}=0$ and $y^{*}=1$ are two possible stable state points, and they are derivatives of $\mathrm{F}(\mathrm{y})$, so $F^{\prime}(1)<0, \mathrm{y}=1$ is an evolutionary stabilization strategy.That is, when implementing the group to choose a protection strategy higher than the level of (P-A)/F, the beneficiary group gradually shifts from a "noncompensation" to a "compensation" strategy."Compensation" is the equilibrium point of evolution stability.

(3) When $x<x^{*}=(P-B) / F, y^{*}=0$ and $y^{*}=1$ are two possible stable state points, so $F^{\prime}(0)<0$, that $\mathrm{y}=0$ is an evolutionary stabilization strategy. That is, when the implementation of the group selects the protection strategy at a level lower than $(\mathrm{P}-\mathrm{B}) / \mathrm{F}$, the beneficiary group gradually shifts from the "compensation" to the "non-compensation" strategy. "Non-compensation" is the equilibrium point of evolution stability.

\subsection{Discussion on Evolutionary Stability Parameters of Related Subjects}

Based on the above analysis, there are five equilibrium points for the ecological compensation evolutionary game model between the implementation groups and the beneficiary groups under the constraint-incentive mechanism. That is $\mathrm{A}(0,0), \mathrm{B}(0,1), \mathrm{C}(1,0), \mathrm{D}(1,1)$, $\mathrm{E}\left(\mathrm{x}^{*}, \mathrm{y}^{*}\right)$. In order to determine the equilibrium conditions for evolution and stability of the relevant subjects in the process of ecological compensation, the dynamic system of game replication is constructed according to equations (1) and (2). According to Friedman's idea, the Jacobian matrix and the corresponding determinant and trace are obtained.

$$
\begin{aligned}
& J=\left(\begin{array}{cc}
\frac{\partial G(x)}{\partial x} & \frac{\partial G(x)}{\partial y} \\
\frac{\partial G(y)}{\partial y} & \frac{\partial G(y)}{\partial y}
\end{array}\right)= \\
& \left(\begin{array}{cc}
(1-2 x)(y F+2 L-2 C+B) & x(1-x) F \\
y(1-y) F & (1-2 y)(x F+B-P)
\end{array}\right)
\end{aligned}
$$


Table2 Local stability analysis

\begin{tabular}{ccc}
\hline $\begin{array}{c}\text { Partial } \\
\text { equilibriu } \\
\mathrm{m}\end{array}$ & $\operatorname{Det}(\mathrm{J})$ & $\operatorname{Tr}\left(\mathrm{J}_{2}\right)$ \\
\hline $\mathrm{A}(0,0)$ & $(2 \mathrm{~L}-2 \mathrm{C}+\mathrm{B}) \cdot(\mathrm{B}-\mathrm{P})$ & $2 \mathrm{~L}-2 \mathrm{C}+2 \mathrm{~B}-\mathrm{P}$ \\
$\mathrm{B}(1,0)$ & $-(2 \mathrm{~L}-2 \mathrm{C}+\mathrm{B}) \cdot(\mathrm{F}+\mathrm{B}-\mathrm{P})$ & $2 \mathrm{C}-2 \mathrm{~L}+\mathrm{F}-\mathrm{P}$ \\
$\mathrm{C}(0,1)$ & $-(2 \mathrm{~L}-2 \mathrm{C}+\mathrm{F}+\mathrm{B}) \cdot(\mathrm{B}-\mathrm{P})$ & $2 \mathrm{~L}-2 \mathrm{C}+\mathrm{F}+\mathrm{P}$ \\
$\mathrm{D}(1,1)$ & $(2 \mathrm{~L}-2 \mathrm{C}+\mathrm{B}+\mathrm{F}) \cdot(\mathrm{F}+\mathrm{B}-\mathrm{P})$ & $-(2 \mathrm{~F}+2 \mathrm{~B}+2 \mathrm{~L}-2 \mathrm{C}-$ \\
& & $\mathrm{P})$ \\
$\mathrm{E}\left(\mathrm{x}^{*}, \mathrm{y}^{*}\right)$ & {$[(\mathrm{B}-\mathrm{P})(2 \mathrm{C}-2 \mathrm{~L}-\mathrm{B})(\mathrm{F}-\mathrm{P}-$} & 0 \\
& $\mathrm{~B})(\mathrm{F}-2 \mathrm{C}+2 \mathrm{~L}+\mathrm{B})] / \mathrm{F}^{2}$ & \\
\hline
\end{tabular}

According to Table 2, the stability of this evolutionary game needs to determine the equilibrium point of the evolution game according to the values of the income parameters of the implementation group and the constraints of the central government and the size of the incentive parameters. It can be seen that the decisionmaking of the implementation groups and the central government is the key to the equilibrium of this evolutionary game. if we assume that $\mathrm{D}(1,1)$ is the only stable strategy, the discussion of its stability parameters can be divided into the following four scenarios:

Scenario1 $\left\{\begin{array}{l}B+F>2 C-2 L \\ B>2 C-2 L \\ B+F>P \\ B>P\end{array}\right.$

Scenario2: $\left\{\begin{array}{l}B+F>2 C-2 L \\ B<2 C-2 L \\ B+F>P \\ B>P\end{array}\right.$

Scenario3: $\left\{\begin{array}{l}B+F>2 C-2 L \\ B>2 C-2 L \\ B+F>P \\ B<P\end{array}\right.$

Scenario4: $\left\{\begin{array}{l}B+F>2 C-2 L \\ B<2 C-2 L \\ B+F>P \\ B<P\end{array}\right.$

Table 3 Partial stability analysis result of scenario 1

\begin{tabular}{cccc}
\hline $\begin{array}{c}\text { Equilibriu } \\
\text { m point }\end{array}$ & $\operatorname{Det}(\mathrm{J})$ & $\operatorname{Tr}(\mathrm{J})$ & stability \\
\hline $\mathrm{A}(0,0)$ & + & + & Unstable \\
$\mathrm{B}(1,0)$ & - & + & Unstable \\
$\mathrm{C}(0,1)$ & - & $+/-$ & Unstable \\
$\mathrm{D}(1,1)$ & - & - & ESS \\
$\mathrm{E}\left(\mathrm{x}^{*}, \mathrm{y}^{*}\right)$ & $+/-$ & 0 & Saddle Point \\
\hline
\end{tabular}

Table 4 Partial stability analysis result of scenario 2

\begin{tabular}{cccc}
\hline $\begin{array}{c}\text { Equilibriu } \\
\text { m point }\end{array}$ & $\operatorname{Det}(\mathrm{J})$ & $\operatorname{Tr}(\mathrm{J})$ & stability \\
\hline $\mathrm{A}(0,0)$ & - & $+/-$ & Unstable \\
$\mathrm{B}(1,0)$ & - & + & Unstable \\
$\mathrm{C}(0,1)$ & - & $+/-$ & Unstable
\end{tabular}

\begin{tabular}{cccc}
$\mathrm{D}(1,1)$ & + & - & ESS \\
$\mathrm{E}\left(\mathrm{x}^{*}, \mathrm{y}^{*}\right)$ & $+/-$ & 0 & Saddle Point \\
\hline \multicolumn{5}{l}{ Table 5 Partial stability analysis result of scenario 3 } \\
\hline $\begin{array}{c}\text { Equilibriu } \\
\text { m point }\end{array}$ & Det $(\mathrm{J})$ & $\operatorname{Tr}(\mathrm{J})$ & stability \\
\hline $\mathrm{A}(0,0)$ & - & $+/-$ & Unstable \\
$\mathrm{B}(1,0)$ & - & + & Unstable \\
$\mathrm{C}(0,1)$ & - & $+/-$ & Unstable \\
$\mathrm{D}(1,1)$ & + & - & ESS \\
$\mathrm{E}\left(\mathrm{x}^{*}, \mathrm{y}^{*}\right)$ & $+/-$ & 0 & Saddle Point \\
\hline
\end{tabular}

Table 6 Partial stability analysis result of scenario 4

\begin{tabular}{cccc}
\hline $\begin{array}{c}\text { Equilibriu } \\
\text { m point }\end{array}$ & $\operatorname{Det}(\mathrm{J})$ & $\operatorname{Tr}(\mathrm{J})$ & stability \\
\hline $\mathrm{A}(0,0)$ & + & - & ESS \\
$\mathrm{B}(1,0)$ & + & + & Unstable \\
$\mathrm{C}(0,1)$ & + & $+/-$ & Unstable \\
$\mathrm{D}(1,1)$ & + & - & ESS \\
$\mathrm{E}\left(\mathrm{x}^{*}, \mathrm{y}^{*}\right)$ & $+/-$ & 0 & Saddle Point \\
\hline
\end{tabular}

From the results of the stability analysis in Table 3-6, we can see that in the scenario one to scenario three, the point $\mathrm{D}(1,1)$ is the only stable strategy. In the fourth case, the point $\mathrm{A}(0,0)$ and $\mathrm{D}(1,1)$ are both the equilibrium points of the game. Copy the dynamic phase diagram from Figure 1. Therefore, only when meeting Scenario 1, Scenario 2 and Scenario 3, there is a unique stabilization strategy (protection, compensation) for the evolutionary game of cross-regional ecological compensation. It can be concluded that the parameters of the central government constraint-incentive mechanism (penalty amount $\mathrm{F}$, bonus amount B) range from: $\left\{\begin{array}{l}F+B>2 C-2 L \text { under this condition, } \\ F>P\end{array}\right.$

There is a unique stabilization strategy when the sum of the amount punishment and rewards by the central government is greater than the loss of the protection of forest resources in the developing regions and the penalty amount is greater than the amount of compensation in developed regions.

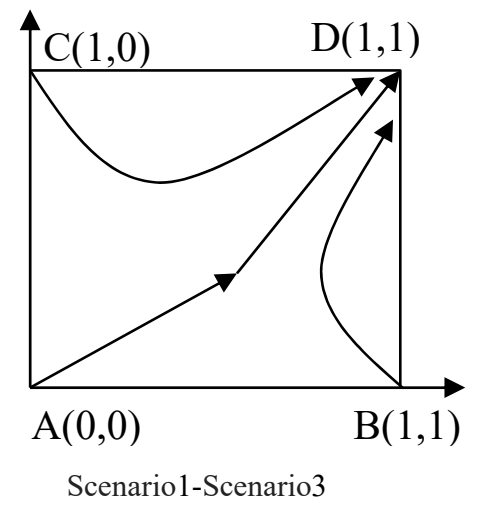

Scenario1-Scenario3 


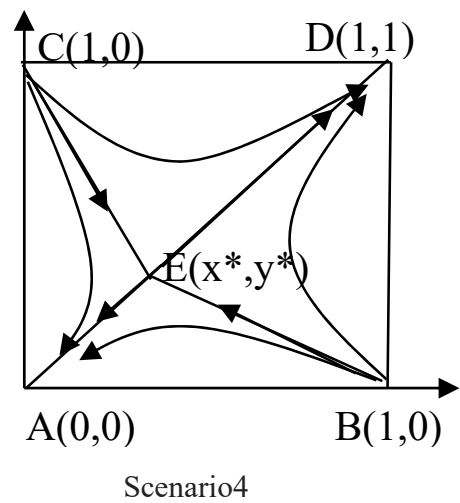

Figure 1 The phase map of the copy dynamics and its evolution stability

\section{Conclusions}

Ecological compensation mechanism is an effective means to protect the ecological environment and balance the interests of all parties.

This paper builds an evolutionary game model for the implementation groups and beneficiary groups by introducing the central government's "constraintincentive" mechanism. We analyzes the processes through which the two parties adopt long-term repeated games, learning and strategy adjustment. The following tho conclusions were reached:

Firstly, in the evolutionary game model, the evolution of the implementation group and beneficiary group is important. However, given the information and external conditions of the counter party in the evolution process, the participants can change their game balance by changing their own payment functions. If the implementation group selects the protection strategy at a level higher than $(\mathrm{P}-\mathrm{A}) / \mathrm{F}$, the beneficiary group gradually shifts from a "no compensation" to a "compensation" strategy. When the beneficiary group selects the "compensation" strategy at a level higher than the $(2 \mathrm{C}-2 \mathrm{~L}-\mathrm{B}) / \mathrm{F}$ level, the implementation group gradually tends to the "protection" strategy from the "unprotected" strategy.

Secondly, after the introduction of the central government's constraint-incentive mechanism, the optimal evolutionary equilibrium point for cross-regional ecological compensation depends on the scope of the central government's penalty and reward parameters. When the sum of the central government's punishment and rewards is greater than that of the developing regions, the ecology can be protected. When the total loss of the environment is 2 times, and the amount of punishment is greater than the amount of compensation in developed regions, there is only a stable and stable equilibrium point (protection, compensation).

\section{Reference}

1. Ming, F, Jun,L.Research progress and debate on ecological compensation theory - based on ecological social relations.China's population resources and environment,2017(03):130-137.

2. Min,F, Lin,M.Reconstruction of Financial Transfer Payment System in China's Ecological Function Area: Based on Extensive Emergy Model Measuring Ecological Spillover Value,Economic Research,2015(03):47-61.

3. Li, F., et al., Application of game model for stakeholder management in construction of ecological corridors: A case study on Yangtze River Basin in China. Habitat International, 2017. 63: 113121.

4. Ji, P., X. Ma and G. Li, Developing green purchasing relationships for the manufacturing industry: An evolutionary game theory perspective. International Journal of Production Economics, 2015. 166: 155 162.

5. Sheng, J., et al., An evolutionary modeling approach for designing a contractual REDD+ payment scheme. Ecological Indicators, 2017. 79: p. 276-285.

6. .Li F, Pan B, Wu Y, et al. Application of game model for stakeholder management in construction of ecological corridors: A case study on Yangtze River Basin in China[J]. Habitat International, 2017, 63:113-121.

7. Engel S, Palmer C. Payments for environmental services as an alternative to logging under weak property rights: The case of Indonesia $\hat{\sim}[\mathrm{J}]$. Ecological Economics, 2008, 65(4):799-809.

8. Ji P, Ma X, Li G. Developing green purchasing relationships for the manufacturing industry: An evolutionary game theory perspective $[\mathrm{J}]$. International Journal of Production Economics, 2015, 166:155-162.

9. Fan J. Local Linear Regression Smoothers and Their Minimax Efficiencies[J]. Annals of Statistics, 1993, 21(1):196-216.

10. Farrell K N. Intellectual mercantilism and franchise equity: A critical study of the ecological political economy of international payments for ecosystem services[J]. Ecological Economics, 2014, 102(2):137-146.

11. Lera-López, F., et al., Rural environment stakeholders and policy making: Willingness to pay to reduce road transportation pollution impact in the Western Pyrenees. Transportation Research Part D Transport \& Environment, 2014. 32: 129-142.

12. Turner, R.K., et al., Valuing nature: lessons learned and future research directions ir. Ecological Economics, 2003. 46(3): p. 493-510. 